\title{
Field Studies of Butterflies: A Trial for the Establishment of Indices to Evaluate the Seasonal Fluctuations and the Ecological States of Forests in Bangladesh
}

\author{
Reza M. Shahjahan ${ }^{1,2}$, M. Abdur Razzak ${ }^{1}$, A. T. M. Fayezul Islam¹, A. S. M. Saifullah ${ }^{1}$ Yamanaka $^{3}$, \\ M. Inoue ${ }^{3}$ and K. Endo ${ }^{3}$ \\ ${ }^{1}$ Institute of Food and Radiation Biology, GPO Box-3787, Dhaka 1000, ${ }^{2}$ Department of Zoology, Faculty of Science, University \\ of Dhaka, Dhaka 1000, Bangladesh, ${ }^{3}$ Deparetment of Physics, Biology and Informatics, Faculty of Science, Yamaguchi \\ University, Yamaguchi 753, Japan.
}

\begin{abstract}
To establish the indices evaluating the ecological conditions of forests in Bangladesh, total number of butterflies counted in 5 observation sites reached 27,805 (76 species, 10 families). Number of butterflies (IND) and species showed bimodal pattern of seasonal fluctuations peaked in April and November-toDecember. The values of I(R5) also showed bimodal seasonal fluctuations peaked in January-to-February and July-to-September. The ratios of IND/I(R5) formed a large peak in November. Results indicate that specics diversities of butterflies high in March-to-July decreased thereafter, the numbers of butterflies increased toward November in the study area.
\end{abstract}

Key words: Butterfly, seasonal fluctuation, population indices, ecological states

\section{Itroduction}

Organisms living in a forest are shown to form a complex community, named a biocoenose, which seems to vary depending on ecological conditions of the forests, such as weather factors and vegetations (Jackson \& Baines, 1999). The biological communities are thought to change slowly with the transitions of vegetations in the forests, but it change suddenly when the vegetations are destroyed by natural disasters, such as storms and floods or by sudden man made changes such as urbanization, deforestation etc. (Saunders, 1976). The butterfly species number as well as numbers of individual butterflies inhabiting in the farms and forests are thought to vary depending on the flora of the area, (Vickery, 1998) since butterfly larvae are demonstrated to show a wide diversities in their food plants depending on its species.

A defined numbers of butterfly species or group of butterflies inhabit in farms and forests of Bangladesh. It was attempted to study butterflies for establishing indices to evaluate the states and transitions of ecological conditions in the forests.

\section{Materials and Methods}

Methods of field observations: Observations of butterflies were carried out in 5 sites set up in JU campus, Savar, Dhaka, in 2003. For observation, the entire period was divided arbitrarily into a 10 day period observation units or segments, thus there were 3 periods a month, 36 such segments a year. On a fine day of 10-day periods, numbers of butterflies coming around these 5 observation sites were counted visually and recorded with respect to each observation site and each species, respectively. Species of butterflies were identified according to "Butterflies in Thailand, Vol. 1 - 6", (Kurain \& Pinratana, 1981, 1983, 1985; Pinratana \&. Eliot, 1982, 1996a,b), using Yamguchi university butterfly expert service. Initially a species identification electronic pictorial key was made by intensive catch butterflies and these were identified in laboratory (Islam et al., 2007). The researcher was trained accordingly for visual observation, to use it in the field. Any unknown species observed during the course of observation was caught and brought to the laboratory and identified using the above expert service and finally put onto the pictorial key. Based on this preliminary field observations, attempts were made to evaluate the differences of ecological conditions among 5 field observation sites,viz., seasonal fluctuations of the numbers of individuals and species of butterflies among these field observation sites. The observation sites were comprised of (i) a typical Gajari forest with a medially high canopy, (ii) a woodland vegetations with bushy shrubs, (iii) Marshy land with typical bogs, (iv) and an aquatic environment with typical lotic pond ecosystem.

Methods for data analysis: In order to minimize the effects of meteorological factors, i. e. temperature and sunshine conditions, on data of field observations, the values of I(R5) and IND/I(R5) were obtained on the numbers of individuals (IND) and species (SP) according to a two-dimensional-curve model (Yamanaka et al., 2006). The value of I(R5) hypothetically shows the required number of butterflies to achieve average 5 individuals per species. The values of $\mathrm{I}(\mathrm{R} 5)$ were estimated by using an equation $\left(X=A_{1} Y^{2}\right.$ and $Y=1 / 5 X ; X$ and $\mathrm{Y}$ show IND and SP, respectively) in addition to the value of IND/I(R5) showing the ratio of IND divided by I(R5).

\section{Results and Discussion}

In these 5 observation sites, a total of 27,805 butterflies were counted (76 species, 10 families). The numbers of butterflies (IND) as well as those of species (SP) showed bimodal seasonal fluctuations peaked in 9th-to-15th and 30 th-to-36 ${ }^{\text {th }}$ in 10-day periods (April-to-May and November-to-December) in all 5 observation sites. The first peaks of the numbers of butterflies formed in 9th-to15th 10-day periods (April-to-May) are smaller as compared to the second ones occurred in 30th-to-36th 10day periods (November-to-December). Besides, the number of species formed the first peaks in 9th-to-15th 10day periods (April-to-May) as the number of butterflies did, but the size of the first peaks were judged as to be larger as compared to those of the second ones (Fig. 1: left panels). 

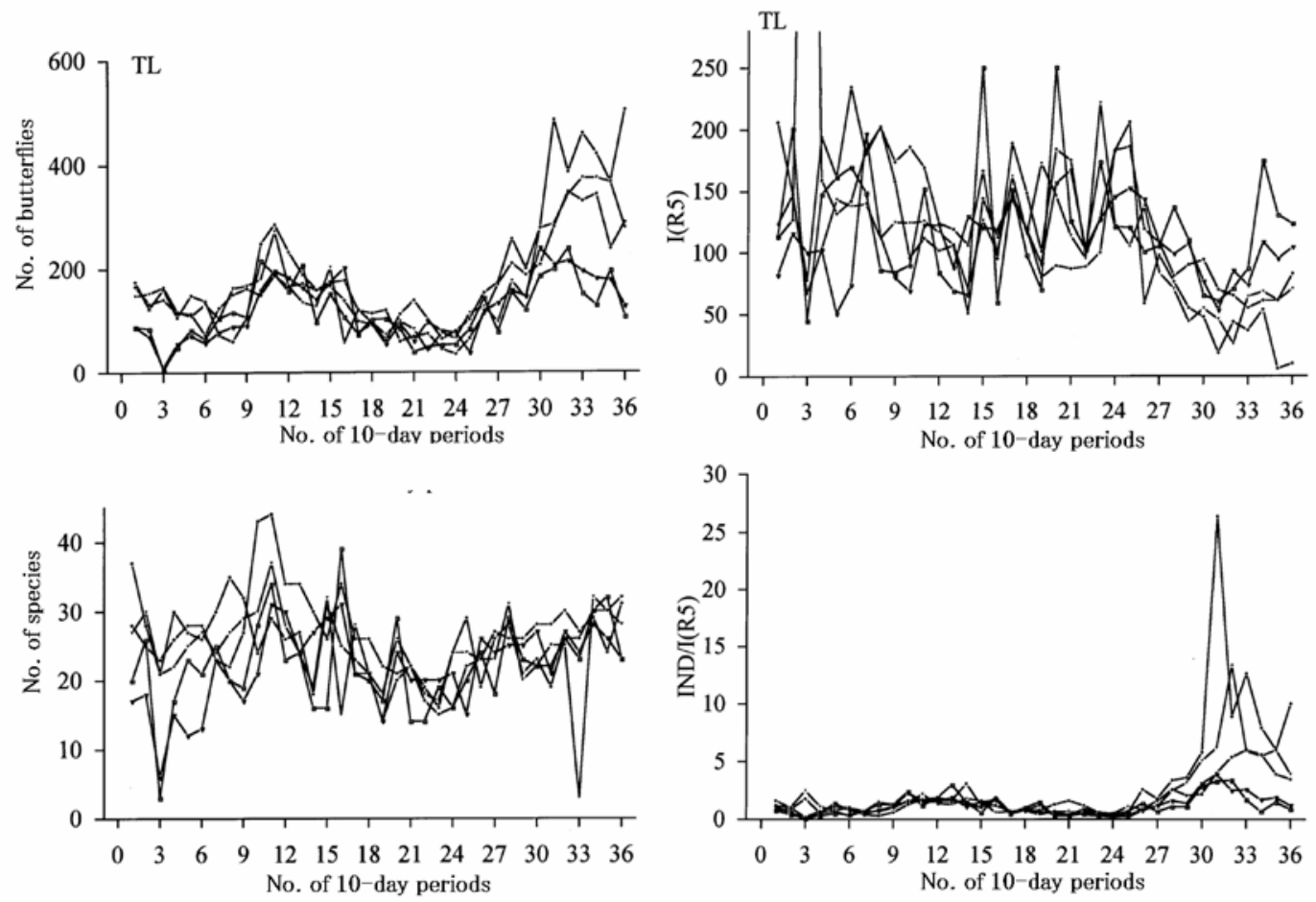

Fig.1. Seasonal fluctuations of the numbers of butterflies and species (left panels) in addition to those of I(R5) and IND/I(R5) (right panels) in 5 observation sites.

The values of I(R5), showed similar patterns of seasonal fluctuations to those of the number of species, whereas the values of IND/I(R5), showed apparent seasonal fluctuations and formed a small peak in 9th-to-15th 10-day periods (Aprilto-May) and a large peak in 30th-to-36th 10-day periods (November- to -December) (Fig. 1: right panels). The results indicated that the first peaks observed in the total numbers of

butterflies of 9th-to-15th 10-day periods (April-to-May) may be formed by both increments of the butterflies and species, but the second peaks which they showed in 30th-to-36th 10day periods (November-to-December) might have be caused by the increments of butterflies in relatively small numbers of species.
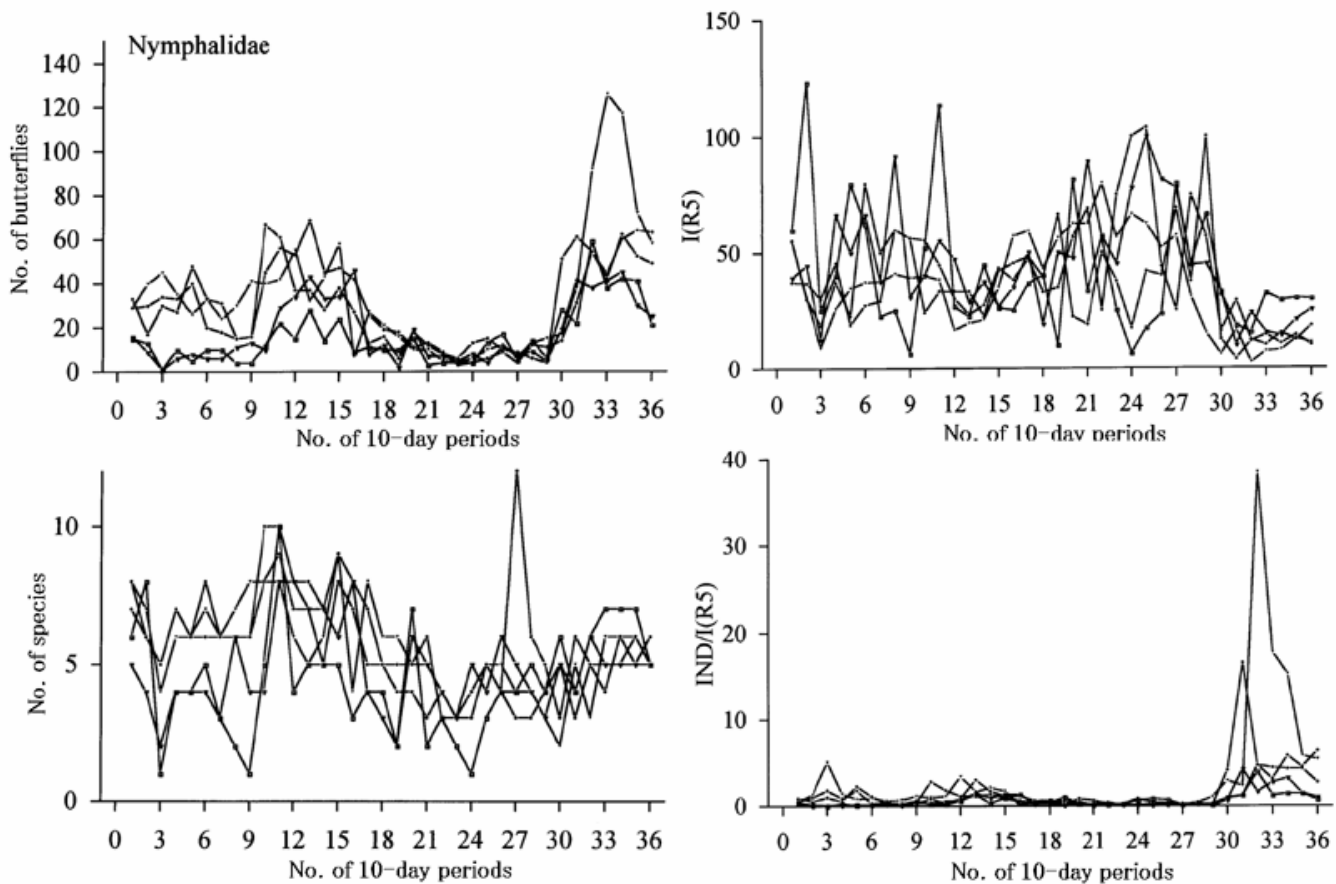

Fig 2. Seasonal fluctuations of individuals and species (left panels) in addition to those of I(R5) and IND/I(R5) (right panels) in Nymphalidae of 5 observation sites. 
In Nymphalidae, the numbers of individuals and species as well as the values of I(R5) and IND/I(R5) showed bimodal seasonal fluctuations (Fig. 2), the patterns of which were similar to those shown by total number of butterflies and species (Fig. 1), indicating that the patterns of seasonal fluctuation of Nymphalidae were supposed to reflected on those of the total number of butterflies in these 5 observation sites. They occupied $14.8 \%$ to $20.9 \%$ in the total number of butterflies in each observation site.

In Papilionidae occupying relatively small proportions $(6.0 \%$ to $8.9 \%)$ in these 5 observation sites, the number of individuals and species showed also bimodal seasonal fluctuations, the peaks of which formed at around 12th-to-18th and 30th-to-33th 10-day periods (May-to-June and November) were judged as to be a little different, respectively (Fig. 3). The values of I(R5) and IND/I(R5) showed three peaked and bimodal seasonal fluctuations, respectively (Fig. 3). But, the second and third peaks of I(R5) were supposed to depend on the decrements of the number of individuals observed in 20thto-27th and 34th-to-36th 10-day periods (July- toSeptember and December), respectively (Fig. 3 upper panels).
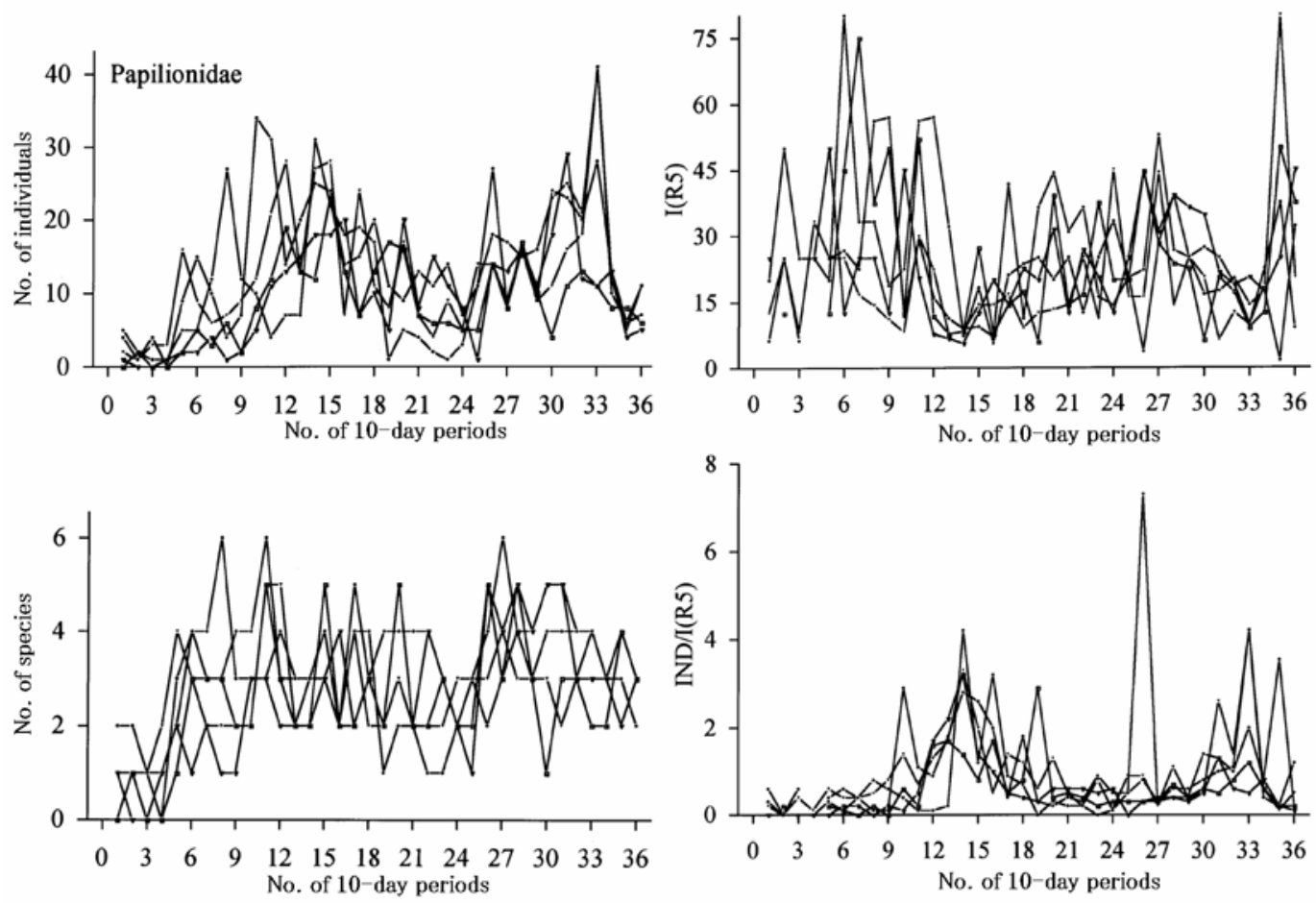

Fig. 3. Seasonal fluctuations of the numbers of individuals and species (left panels) in addition to those of I(R5) and IND/I(R5) (right panels) in Papilionidae of 5 observation sites.

Pieridae was the largest butterfly family (27.3\% to $37.3 \%$ ) in these 5 observation sites. The number of individuals and species showed apparent bimodal peak in 9th-to-18th and 28th-to-35th 10-day periods (April-to-June and the end of October-to-December), respectively (Fig. 4, left panels). The patterns of the fluctuations were similar to those obtained by the total number of butterflies and species (Fig. 1, left panels). The values of I(R5) and IND/I(R5) showed three and two peaks, respectively. The peaks of I(R5) seemed to be formed coordinately with the decrements of the numbers of species, whereas the two peaks of IND/I(R5) may be formed coordinately with the increments of the number of individuals and species (Fig. 4 , right panels).

The seasonal fluctuations of the numbers of individuals and species as well as the values of I(R5) and
IND/I(R5) seemed to be reflected to the patterns of seasonal fluctuations in those obtained by the total numbers of butterflies, respectively.

Lycaenidae consisting of the largest number of (or 25) species in JU, occupied relatively large proportions in numbers of individuals in 5 observation sites, respectively. The number of individuals (IND) as well as those of species (SP) formed two peaks in 4th-to-12th and 33th-to1st 10-day periods (February-to-April and December-toJanuary), respectively. The number of individuals being small in the 4th-to-7th and 20th-to-27th 10-day periods, cold and rainy seasons reached a maximum in 36th 10-day period in 3 of 5 observation sites. The values of I(R5) formed peaks in 4th-to-7th and 20th-to-27th 10-day periods when the number of individuals reached a peak, respectively. 

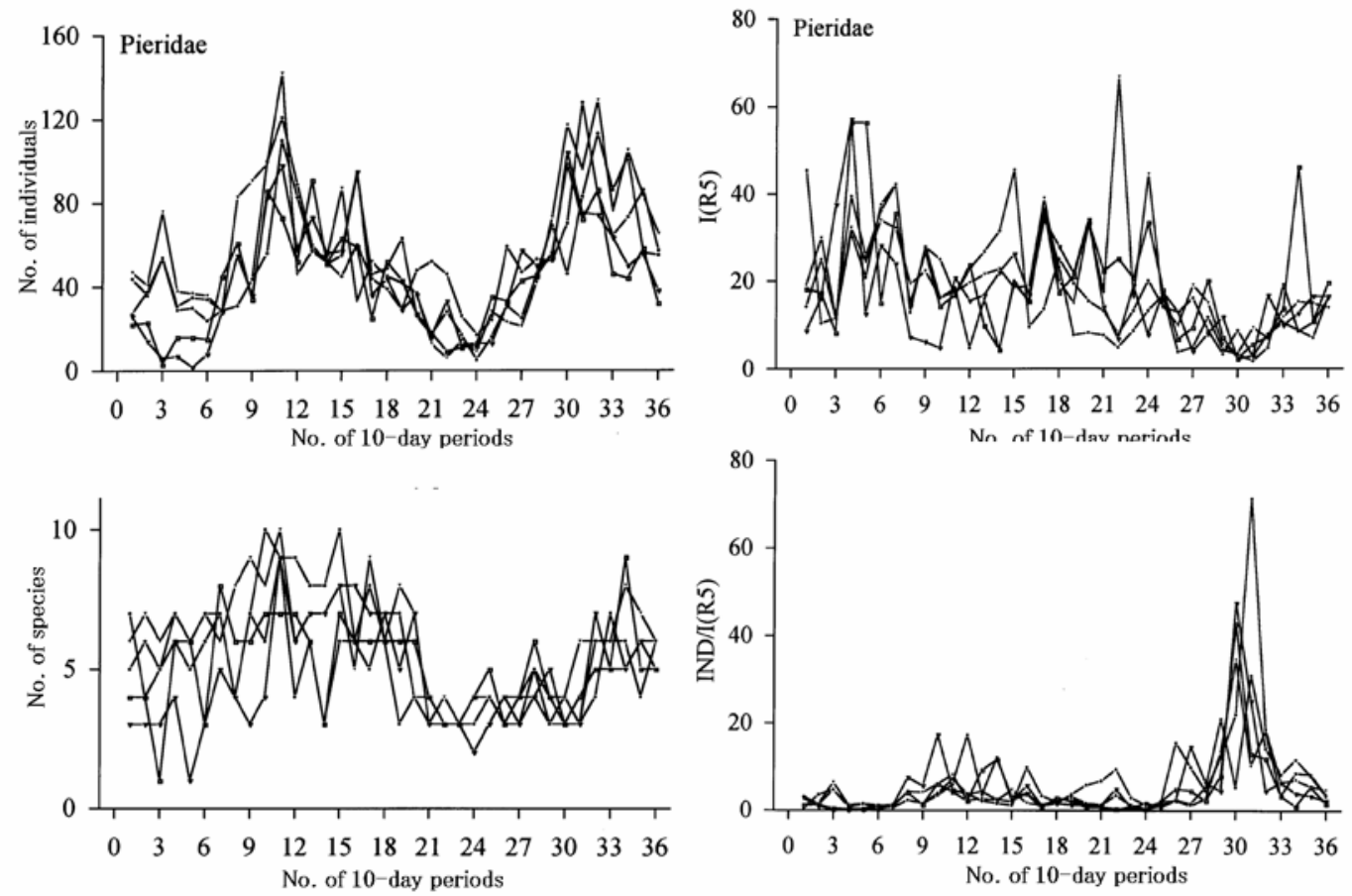

Fig.4. Seasonal fluctuations of the numbers of individuals and species (left panels) in addition to those of I(R5) and IND/I(R5)(right panels) in Pieridae of 5 observation sites

Literature search reveal no such works on distribution of field population of butterflies done in Bangladesh apart from a few sporadic works on survey and taxonomy by Ameen \& Choudhury (1968), Baksha \& Choudhury (1983, 1985) Bashar et al. (2006). Threre is a bimodal distribution of the different groups of butterfly (Pierid, Papillionid, Nymphalid, Lycanid) with two peaks, one in the summer and the other in the winter, although there were a few shift of the population

peaks among the different groups. This distribution in general correlates with the occurrence of vegetation in these seasons that support the larval development. The bimodal distribution of butterfly support the occurrence of summer and winter diapauses in Lepidoptera (Endo et al., 1985). The present study provides a gross distributional estimate of the population of butterflies along with its habitat type that could be helpful for the managerial purpose of the butterfly farming.
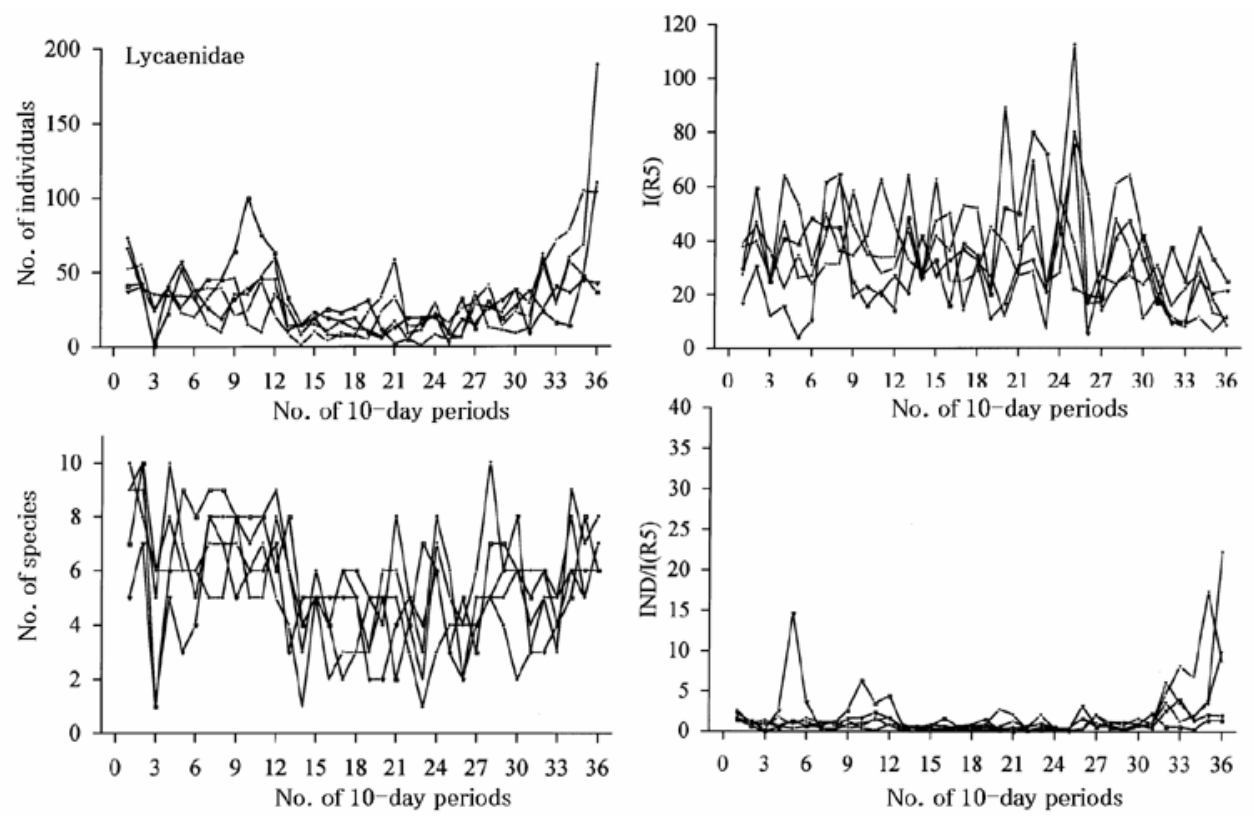

Fig.5. Seasonal fluctuations of the numbers of individuals and species (left panels) in addition to those of I(R5) and IND/I(R5) (right panels) in Lycaenidae of 5 observation sites. 


\section{Acknowledgements}

This work was conducted under IFRB (Bangladesh) and YU (Japan) agreement for research cooperation (20012005), RMS and KE were the respective national counterparts.

\section{References}

Ameen, M. and S.H. Choudhury 1968. Diversity and phanton competition among African acarine butterflies. Biol. Linn. Soc. 30,291-297.

Baksha, M. \& Choudhury J. 1983. Entomo-fauna of the forests in the Bangladesh Forests I Lepidoptera: Pieridae. Univ j zool.Rajshahi Univ. 2: 53-60.

Baksha, M. \& Choudhury J. 1985 Entomo-fauna of the forests in the Bangladesh Forests I Lepidoptera:Pieridae. Univ j zool.Rajshahi Univ. 4: 1-7.

Bashar, M.; Mamun, M. . Khan, H \&^ Choudhury, A. 2006. Wing venation as a factor for the identification of Nymphalid butterflies in some forests of Chittagong and Cox's Bazar (Bangladesh). Bangladesh.j.zool. 34,187194.

Endo K., Maruyama, Y., Kasai , K 1985. Environmental factors controlling seasonal morph determination in the small copper butterfly, Lycaena phlaeas daimio Seitz. J. Insect Physiol 31, 525-532.

Islam, ATMF, Razzak, M.A., Saifullah, A.S.M. Shahjahan, RM , Endo, K, Yamanaka, A., Kometani, M.\& Inoue M. 2007. Common Butterflies in Bangladesh, 33pp (with 15 plates), Published by Institute of Food and Radiation Biology.
Jackson, B. \& Baines, B. 1999. Mindful of butterflies, The Book Guild Ltd, Sussex 160pp.

Kurain, E. J. \& Pinratana, A. 1981. “ Buttn Thailand vol.4, Lycaenidae.” The Viratham Press, Bangkok, pp. 215

Kurain, E. J. \& . Pinratana. 1983. “ Butterflies in Thailand vol.2, Piraridae and Amathysiidae" reviced ed. The Viratham Press, Bangkok, pp. 71.

Kurain, E J \& Pinratana, A. 1985. “ Butterflies in Thailand vol.5, Hesperiidae” The Viratham Press, Bangkok, pp. 152.

Pinratana, A \& Eliot, J. N. 1982. “ Butterflies in Thailand vol.1, Papilionidae and Danaidae” 2nd and reviced ed. Bosco Offset, Bangkok, pp. 78.

Pinratana, A \&. Eliot, J. N. 1996a. "Butterflies in Thailand vol.6, Satyridae” The Viratham, Press, Bangkok, pp. 61.

Pinratana A \& Eliot, J. N. 1996b. “ Butterflies in Thailand vol.3, Nymphalidae” 2nd and revised ed. Bosco Offset, Bangkok, pp. 140.

Saunders D.S. 1976. The Insect Clocks. Pergammon Press NY, 347pp.

Vickery, M. 1998. Gardening of Butterflies. The British Butterflies Conservation Society, Dedham 44pp.

Yamanaka A, Islam, A.T.M.F. Shahjahan, R.M. Saifullah, A.S.M., Inoue, T., Ito, Y, Masaki, H , Watanabe, M, \& Endo, K. 2006. A trial of moth study as an indices for evaluating quantitative changes of ecological state in forests of eastern central part of Yamaguchi Prefecture. Yamaguchi University press 561 pp. (in Japanese)

Manuscript received on 21.07.2008, accepted on 20.10.2008 